\title{
Arctic modeling data resources: the data archives at the ARCSS Data Goordination Genter and the National Snow and Ice Data Center, U.S.A.
}

\author{
David L. MaGinnis, Matthew D. Cross \\ CIRES, Campus Box 44.9, University of Colorado, Boulder, CO 80303, U.S.A.
}

\begin{abstract}
A major concern of the cryospheric community is the availability of reliable data for use with various types of models. The National Science Foundation's Arctic System Science program (ARCSS) integrates specific Arctic investigations ranging from the Greenland Ice Sheet Project, the Land-Atmosphere-Ice Interactions, the OceanAtmosphere-Ice Interactions and its associated Surface Heat Energy Budget of the Arctic program to the recently initiated Human Dimensions of the Arctic System project. All data collected from these investigations are archived at the ARCSS Data Coordination Center and the National Snow and Ice Data Center at the University of Colorado, U.S.A. A primary goal of the ARCSS Data Coordination Center is to facilitate better use of observed data within cryospheric modeling efforts. Working with the ARCSS Data Management Group and the Modeling Working Group, we are developing data appropriate for the cryospheric modeling community. This paper summarizes the data currently available at the ARCSS Data Coordination Center, and details the mechanisms by which Arctic researchers can access these data.
\end{abstract}

\section{INTRODUCTION}

Since 1994, the National Snow and Ice Data Center (NSIDC) at the University of Colorado at Boulder has been funded as the Arctic System Science (ARCSS) Data Coordination Center. The National Science Foundation ARCSS program includes the Ocean-Atmosphere-Ice Interaction (OAII), the Land-Atmosphere-Ice Interaction (LAII) and the Greenland Ice Sheet Project Two (GISP2) projects that already have extensive data holdings archived at the ARCSS Data Coordination Center. We also collaborate with the National Oceanic and Atmospheric Administration's (NOAA) National Geophysical Data Center (NGDC), where the primary data for the Paleoclimates of Arctic Lakes and Estuaries (PALE) are located (PALE data holdings are extensive, but are not discussed or mapped in this paper in detail, although the last section describes how to access the data.

Several new ARCSS research programs are beginning, including the Surface Heat Energy Budget of the Arctic Ocean (SHEBA) and the Human Dimensions of the Arctic System (HARC). Finally, a new focus of ARCSS is the Synthesis, Integration and Modeling Studies (SIMS) initiative. This effort attempts to coordinate the other ARCSS research programs, and to emphasize modeling as a tool to allow a better understanding of the Arctic system.

This paper is organized as follows: first, a brief description of ARCSS modeling activities is provided, followed by a discussion of data holdings at the ARCSS Data Coordination Center. We conclude with information on how to access the data holdings.

\section{ARCSS MODELING}

According to the Arctic Research Consortium (1993), a primary goal for the ARCSS program is:

(1) to understand the physical, chemical, biological and social processes of the Arctic system that interact with the total Earth system and thus contribute to or are influenced by global change in order

(2) to advance the scientific basis for predicting environmental change on a decade-to-centuries time-scale and for formulating policy options in response to anticipated impacts of changing climate on humans and social systems.

In order to accomplish this goal, many ARCSS investigators employ various models to support their research. Ranging from global-scale general circulation models (GCMs) to specific small-scale process models, the ARCSS community attempts to integrate across spatio-temporal scales to understand better the role of the Arctic in a global change context.

Several general modeling goals are recommended for the ARCSS program that integrate across broad categories (Arctic Research Consortium, 1996). Model verification experiments strive to resolve discrepancies between observations and modeled outputs (as well as model-to-model comparisons), to simulate past as well as present-day climate, and to narrow uncertainties between model projections for the same variables. A second broad modeling goal is one that provides insight and understanding to simulate successfully past, present and future environments. This in- 
cludes modeling the human dimension and policy-related aspects of the Arctic system (e.g. population dynamics, sustainable development, environmental resource use, etc.). Other specific modeling concerns that provide insight include scaling, assessing the importance of specific processes (e.g., carbon fluxes) and testing model parameterizations.

Models are often used for specific forecasts and environmental reconstructions. The ARCSS program aims to define the role of the Arctic in the global climate system, to reconstruct past climates in order to understand the responses of the Arctic to a variety of global climatic conditions, and to provide predictions that anthropogenic discharges will have on the Arctic system and to analyze their feedbacks to the global environment. These modeling goals also provide input for ARCSS data-collection efforts. Collaboration between modeling efforts and field data collection will help narrow uncertainties in model projections. In addition, such efforts help guide decisions regarding the collection of new data.

In order to achieve these goals, the ARCSS program focuses on four main types of models. First, integrative system models include global and regional climate-system models. Typically, these couple atmospheric GCMs, or mesoscale models, to oceanic GCMs, sea-ice models (thermodynamic and dynamic) and land-surface models. Such models are especially useful for studying interactions within the Arctic system and links to the global system. On a smaller scale, the ARCSS program supports use of landscape or watershed models. These investigate specific ecosystems and the functions and dynamics of biogeochemical and hydrologic processes. Second, process models tend to focus more on a specific discipline. Process models usually examine smallscale details that may be utilized in larger-scale integratedsystem models. For example, a process model in the LAII program may investigate nutrient controls over plant production that then feeds into an atmospheric boundary-layer model. This knowledge can then be integrated into the landsurface models in an integrated-system model.

Third, models of human/societal interactions range from policy and economic models to sustainable land-use models, although these are not as well developed as those discussed above. Combining physical and social science aspects of the Arctic system is a continuing challenge. Finally, qualitative or conceptual models are also valuable to the ARCSS program. Not all models develop specific numerical representations of physical parameters; qualitative models help provide greater insight to Arctic system dynamics, and will provide guidance for physical model development.

\section{DATA HOLDINGS IN THE ARCSS DATA COORDIN- ATION CENTER}

This section describes the majority of our current data holdings (although new data are being submitted continually this list was up-to-date at the time of going to press). We divide our data into two broad categories. First, some datasets cover large geographical regions or are transects. These data include remotely sensed data, multiple sensor data (e.g. the Historic Arctic Rawinsonde Archive developed from drifting buoys) and multiple site data (e.g. the Global Historical Climatology Network, a multiple variable record that has been developed from data from weather stations). Second, some data have been collected in transects over large areas (e.g. the Arctic Ocean Section voyage across the Arctic Ocean). Since these data are not point specific, they are not mapped in Figure 1; however, those data with specific locations (e.g. field camps or meteorological stations) are mapped showing the specific variable categories. For modelling purposes, both data forms can be valuable.

\section{Regional data types}

The following spatially oriented datasets are currently available from the ARCSS archive.

\section{Arctic water-vapor characteristics}

These data contain climatological parameters suitable for validating Arctic climate simulations from GCMs, and for improving the retrieval of Arctic surface properties from satellite information. The data are compiled from existing

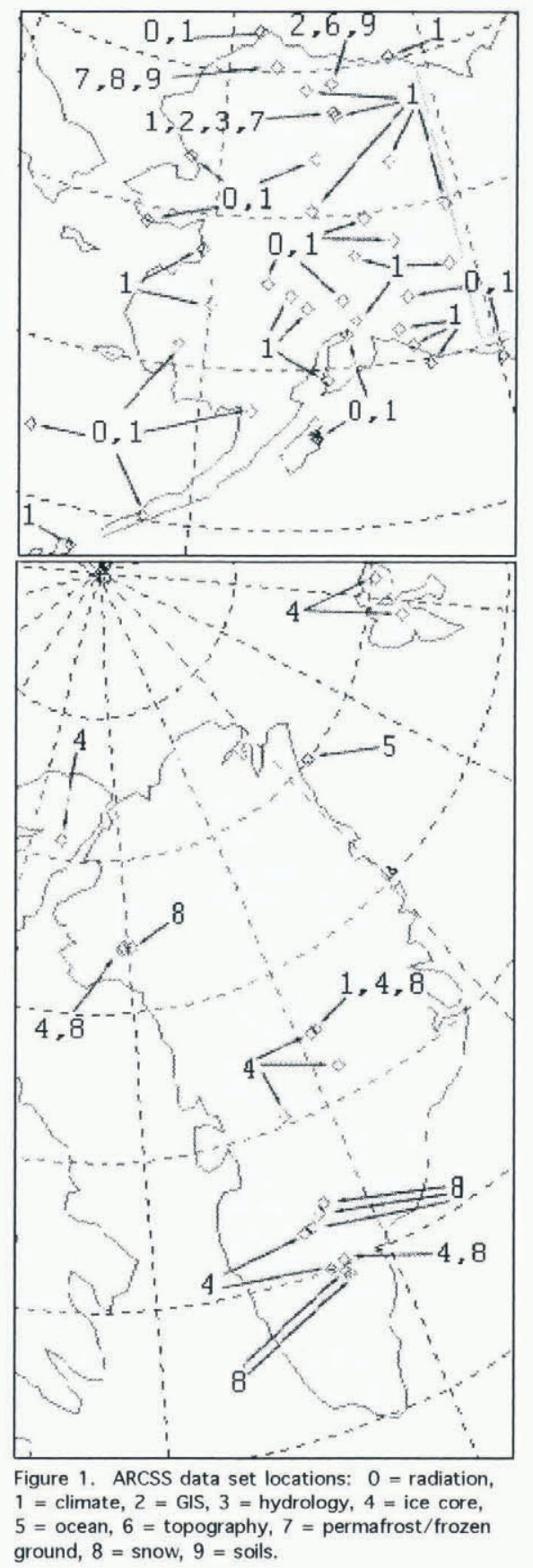

Fig. 1. ARCSS dataset locations: 0, radiation; 1 , climate; 2 , GIS; 3, hydrology; 4, ice core; 5, ocean; 6, topography; 7, permafrost or frozen ground; 8, snow; 9, soils. 
rawinsonde archives into gridded monthly means from 1954 to 1991 including fixed station soundings; ship soundings obtained from the National Center for Atmospheric Research; and drifting ice-station soundings obtained through the U.S. Russian Joint Committee on Environmental Protection.

\section{Artic cyclone tracks}

This dataset comprises a 28 year record (1 May 1966-31 December 1993) of twice-daily extra-tropical cyclone statistics for the Northern Hemisphere. Sea-level pressure (SI.P) fields on the $47 \times 51$ Octagonal National Meteorological Center (NMC) grid are used to determine the position and central pressure of each cyclone, cyclogenesis cyclone formation or cyclolysis (cyclone demise) events, as well as the local Laplacian $\left(10^{-5} \mathrm{mbm}^{2}\right)$ and sea-level pressure tendency (SLPT) $\left(\mathrm{mb} 12 \mathrm{~h}{ }^{\prime}\right)$ at each cyclone center. A sample FORTRAN program to read the data file is included.

\section{Historical Arelic Rawinsonde Archive ( HARA)}

The dataset contains soundings from $95 \mathrm{Arctic}$ land stations north of $65 \mathrm{~N}$. Vertical profiles to $300 \mathrm{mb}$ of temperature, geopotential height, dew-point depression, and winds for mandatory and significant levels from the 1950 s to 1991 are available on CD-ROM.

\section{ETOPO5 elerations}

The data file contains ETOPO5 elevations poleward from $50 \mathrm{~N}$. The data are provided to NSIDC by NGDC and are available via FTP and CD-ROM.

\section{Artic Ocean Section (AOS) transed}

Oceanic, atmospheric and ice information was collected during a joint Canadian-U.S. cruise throughout the Arctic in the summer of 1994. Termed the Arctic Ocean Section (AOS), the goal was to increase substantially the observational base necessary for understanding the role of the Arctic in global change. AOS data types include conductivity. temperature and depth (CTD) information, contaminant measurements, volatile organic compounds, sulfur dioxide, acid gases, major ions, stable isotopes, atmospheric acrosols and condensation nuclei, dimethyl sulfide, ozone, carbon monoxide, carbon dioxide and organohalides.

\section{Canadian and Russian rivers data}

Daily discharge rates for 20 Canadian Arctic rivers and monthly and maximum yearly flow rates for selected Russian Arctic rivers are available. Water depths for the MacKenzie River are also included. Russian data were acquired through a data-exchange agrecment with the State Hydrological Institute in St Petersburg, Russia, a part of the Federal Service for Hydrometcorology and Environmental Monitoring, Moscow, Russia.

\section{Ouiput data from L.AH-BATS.ARCSy.M modet run}

The Arctic Region Climate System Model (ARCSyM) has been run over Alaska's North Slope using the Biospheric Atmospheric Transfer (BATS) vegetation model. Both six hourly and monthly mean values for most standard climatological variables at 23 sigma levels are provided and specified to a $15 \times 15$ grid centered at $69^{\circ} \mathrm{N}, 149^{\circ} 08^{\prime} \mathrm{W}$ with $20 \mathrm{~km}$ grid resolution; additional data on a $70 \times 40$ grid centered on $68 \mathrm{~N}$ and $152^{\circ} \mathrm{W}$ with $20 \mathrm{~km}$ grid resolution are also archived.

\section{Canadian Arctic radialion}

Hourly radiation data are available from 17 stations poleward of $50 \mathrm{~N}$ latitude. These were acquired from Environment Canada and include global solar radiation, sky radiation, reflected solar radiation and net radiation.

\section{AVHRR (I km) imagery collected onboard the Polar Sea}

AVHRR images were downloaded to the USCGC: Polar Sea during the NSF/ARCSS/OAII-funded Northeast Water Polynya (NEW) Project. There are 126 AVHRR images available from NOAA 10, 11 and 12 from 19 July 1993 to 16 August 1993. An on-line users guide to the $1 \mathrm{~km}$ AVHRR polar archive is available from NSIDC.

\section{Global FAO soil unit data}

Global soils data in $\mathrm{EAO}$ soil units at $1^{\circ} \times \mathrm{I}^{\circ}$ resolution for 27 soil types are available via FTP and CD-ROM. A FORTRAN program is arailable to assist in data access.

\section{Global seasonal snow dissification system}

Six classes of seasonal snow cover (including water and ice) were developed from the physical properties of the snow (depth, density, thermal conductivity, number of layers, degree of wetting, etc.), which were then empirically related to climate using three variables (precipitation, wind and air temperature). The data are global in coverage and are formatied on a $0.5^{\circ} \times 0.5^{\circ}$ grid.

\section{Matthew's vegetation dala}

The data files contain information on vegetation types, cultivated areas, wetlands and inundated aerial fraction for the entire Earth at $1^{\circ} \times 1^{\circ}$ resolution. The global distribution of 32 vegetation types is based on the Unesco classification system. A cultivation dataset describes the global distribution of cultivation intensity, distinguishing five classes. The wetlands dataset characterizes the global distribution of wetland ecosystems in five classes. The inundated acrial fraction data are the global distribution of inundated land. These data can be combined with the wetlands data to calculate global wetland area.

\section{Site-specific data types}

The following data categories are referenced in Figure $I$. Generally, they are site-specilic. These data are commonly used for model-validation studies where specific site detail is desired.

\section{Radiation}

These hourly records from 17 Alaska stations $(1961-90)$ were acquired from the NOAAs National Climatic Data Genter for the Solar and Meteorological Surface Observation Network SAMSON) project. These data include solar, directnormal and difluse-sky radiation.

\section{Climate}

A suite of climate data are available from many study sites on the North Slope of Alaska. Air temperature, precipitation, relative humidity, wind direction and speed, pressure and water vapor flux data are available from the Kuparuk River basin study site and Barrow, Alaska. The temporal scale ranges from six minutes to annual averages depending on the data for $1975-95$. The data for the Global Historical Climatology Network (GHCN) for Alaska are also included in this category. These monthly data are available via FTP and (CD-ROM. 


\section{Geographic information system data}

Geographic information system (GIS) data are compiled for the Kuparuk River basin, Alaska, an ARCSS/LAII study site. These include information on vegetation, geomorphology, hydrology, elevation, geology and climate at varied scales.

\section{Hydrology}

The North Slope, Alaska, Long Term Ecological Research (LTER) site is a focal point for many data collection projects. The data from this area include river discharge, nutrients, physics, chemistry, sestonic and epilithic chlorophyll, insects, isotopes, fish growth (includes length and weight), zooplankton, primary production, plant biomass, air temperature, wind speed and direction, relative humidity, precipitation, photosynthetically active radiation (PAR), net and solar radiation, soil temperatures, barometric pressure, Toolik Lake temperatures and Kuparuk River water level. The data were collected from 1975 to 1991.

\section{Ice cores}

The ARCSS data archive at NSIDC is the primary storage and distribution center for GISP2 data. Electro-conductivity measurements (ECM), major-ion concentrations, $\delta^{18} \mathrm{O}$, and automated weather-station data were recorded at the GISP2 site. Core data from other Arctic and Antarctic locations are also available through collaboration with NGDC. Information and data from Crete, Milcent, Agassiz, Dye2, Dye3, GRIP, and Camp Century in Greenland; Vostok and Byrd in Antarctica; two cores in Spitsbergen; the Quelccaya core from Peru; and the Lewis core from Kenya are all available via FTP. Shallow-core data from Greenland and Antarctica are also available.

\section{Ocean}

Hydrographic (CTD), nutrients, phytoplankton type and concentration, climate, and acoustic Doppler current profiler (ADCP) data were collected from May to August 1992 and 1993 for the NEW study off the coast of northeast Greenland.

\section{Elevation}

Digital-elevation model (DEM) data are available for Toolik Lake, Kuparuk River basin, North Slope of Alaska.

\section{Permafrost and frozen ground}

Data holdings include hourly and four-hourly soil temperature, soil moisture, thaw depth, snow depth, and air temperatures from many sites across the North Slope of Alaska from 1962 to 1993.

\section{Snoze}

Snow-pit data from the Arctic and Antarctic are archived. Most of the Arctic data came from Greenland and the Kuparuk River basin study site on the North Slope of Alaska. Antarctic data (not shown on the map) from various sites across the continent are also available. Typically, the data contain surface snow samples, snow depths, stratigraphy, major ions, stable isotopes, oxygen isotopes, radionuclide information and general weather observations. The snow pits range in size from one to six meters in depth and the data are available from 1984 to 1993.
Soils

Data from Barrow (the Soil Conservation Service Soil Taxonomy of 1992) and the Kuparuk River basin (1986 ARCSS investigation) include soil consistency, texture, moisture, pedon information, flooding (frequency and duration), erosion, runoff, soil temperature, precipitation, bedrock, major land-resource areas, horizon information (thickness, soil pores, rock fragments, roots, soil-surface features, effervescence), mineralogy, oxilates and vegetation.

\section{DATA ACGESS}

Convenient access to the ARCSS data holdings is a key feature of the ARCSS Data Coordination Center program. The data described above can be accessed through a variety of methods. The Internet World Wide Web (WWW) is the primary access tool to the ARCSS Data Coordination Center home page at http://arcss.colorado.edu/. This web page also contains information beyond the data holdings.

All data described above may be accessed through the Data button on the web page. Hitting this button sends the user to another page where ARCSS datasets may be accessed directly as well as providing a direct link to NSIDC. The ARCSS data are divided into specific data categories - primarily the same as those mapped in Figure 1 and discussed in the third section - and may be accessed via direct FTP. As new datasets arrive they are staged into the appropriate category and made available.

Also included on the ARCSS home page is a wealth of additional information. A directory of ARCSS-related people includes both advisory committee members and ARCSS principal investigators. Direct e-mail access to directory listings is also provided. Each ARCSS program has a full description including field summaries and recent news from each project.

Another major feature is a calendar of events, meetings, and abstract and paper deadlines. Hot buttons on the calendar direct the user to conference information and calls for papers. The final section of the home page is a "real-time" weather link for Arctic researchers. Specific regions where field camps are located provide weather forecasts and conditions.

\section{CONCLUSION}

The goal of the ARCSS Data Coordination Center is to provide a long-term archive for data collected under the auspices of the ARCSS program. A major focus of archiving data is to make them readily available. Beyond the direct data access via the WWW, we also can provide the data in a variety of other forms. The primary contact for receiving ARCSS data besides the WWW, is to e-mail info@arcss.colorado.edu.

\section{REFERENCES}

Arctic Research Consortium. 1993. Artic system science: a plan for integration. Fairbanks, AK, Arctic Research Consortium of the United States.

Arctic Research Consortium. 1996. Arctic System Science Modeling Workshop report - draft. Fairbanks, AK, Arctic Research Consortium of the United States. 